\title{
Binswanger's Disease: Progressive Subcortical Encephalopathy or Multi-Infarct Dementia?
}

\author{
Kewei Huang, Lijuan Wu, and Yi Luo
}

\begin{abstract}
Since Binswanger's description of subcortical arteriosclerotic encephalopathy in 1894, numerous cases have been reported. Several authors doubt the validity of this malady, although the majority consider it to be a disease entity. We report seven cases with this type of pallor of myelin, only two of which are accompanied by a history of dementia. Among the seven cases, two had arteriosclerosis of penetrating arteries and arterioles in cerebral white matter. Electron microscopy showed splitting of myelin sheaths, probably the result of edema. In reviewing the blood supply of the cerebral white matter, we conclude that no pathological alterations of medullary branches of the cerebral arteries, the same vessels supplying the white matter, can give rise to such diffuse pallor of white matter and spare the arcuate fibres. This pallor can only be due to cerebral edema, most likely of hypoxic-ischemic, hypotensive, or acidotic origin. We also contend that arteriosclerosis can only cause dementia through multiple infarcts or lacunae, if it indeed leads to dementia.
\end{abstract}

RÉSUMÉ: La maladie de Binswanger: Une démence due à des infarctus multiples? Depuis la description de l'encéphalopathie artériosclerotique sous-corticale par Binswanger en 1894, plusieurs cas ont été rapportés. Plusieurs auteurs doutent la validité de cette maladie, bien que la majorité la considèrent comme une entité médicale. Nous rapportons sept cas atteints de ce type de pâleur de myéline, dont seulement deux sont accompagnés d'une histoire de démence. Parmi les sept cas, deux étaient l'artériosclérose des artères et des artérioles pénétrantes dans la substance blanche cérébrale. La microscopie électronique montra l'éclatement des gaines de myéline, probalement le résultat de l'oedème. En examinant l'approvisionnement sanguin de la substance blanche cérébrale, nous concluons qu'aucune altération pathologique des rameaux médullaires des artères cérébrales, les mêmes vaisseaux qui fournissent la substance blanche, ne peuvent causer une telle pâleur diffuse de la substance blanche et au même temps éviter les fibres arciformes. Seulement cette pâleur peuvent être le résultat de l'oedème cérébrale, vraisemblablement d'origine hypoxiqueischémique, hypotensive, ou acidotique. Nous constatons également que l'artériosclérose peut causer la démence seulement par des infarctus multiples ou par des cavités, si en verité elle produit la démence.

Can. J. Neurol. Sci. 1985: 12:88-94

In 1894 Binswanger described a group of eight patients with a clinical picture of dementia under the term "encephalitis subcorticalis chronica progressiva". He attributed the subcortical white matter degeneration to deficient blood supply resulting from atherosclerosis, but he failed to support his view with detailed histological examination of the brains, merely describing the gross features of the brain of one patient who also had syphilis. ' Since then, numerous similar cases have been reported. Mikol estimated that about thirty cases verified by autopsy had been published up to $1968 .^{2}$ Burger et al. reported one case of subcortical arteriosclerotic encephalopathy (SAE) which showed diffuse white matter degeneration, identical to the subcortical arteriosclerotic encephalopathy (SAE) of Binswanger's disease. ${ }^{3}$ Loizou et al, recently reported that subcortical anteriosclerotic encephalopathy (SAE) could be diagnosed in life by CT scan. ${ }^{4}$ Based on a neuropathological study of 28 cases of psychoses with cerebral arteriosclerosis, Rothschild suggested that "traces of Binswanger's subcortical encephalitis are frequently observed in the brains of patients with arteriosclerotic psychoses, but the pathologic picture described by him as an entity scarcely merits consideration as a separate form of the disorder". 5 Olszewski proposed that since Binswanger's disease is not a well defined clinicopathological entity, the term should not be used in the neuropathological nomenclature. ${ }^{6}$ After studying 4 cases, De

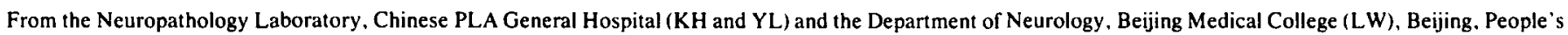
Republic of China

Received August 28, 1984. Accepted in revised form March 23, 1985.

Reprint requests to: Dr. K. Huang. Neuropathology Laboratory, Chinese PLA General Hospital, Beijing. People's Republic of China 
Reuck et al. came to the conclusion: "The proposed pathogenesis and absence of correlation between the clinical and neuropathologic findings in Binswanger's progressive subcortical encephalopathy make it unnecessary to consider this entity a separate type of multi-infarct dementia. ${ }^{, 7}$ From a survey of the literature, it is evident that controversy over the entity of Binswanger's progressive subcortical encephalopathy still exists. We have recently examined the brains of 6 patients with cerebrovascular disease and I patient with metastatic carcinoma, all of whom showed neuropathological changes compatible with the diagnosis of Binswanger's encephalopathy.

\section{Material and Methods}

The postmortem brains were fixed in a $4 \%$ formaldehyde solution for two weeks, after which coronal sections were made. Aftergross pathological examination, paraffin-embedded sections were stained for microscopic examination with hematoxylineosin, Weil's method for myelin, and Bielschowsky stain for axis cylinders. A piece from the pale area of each case previously fixed in $4 \%$ formaldehyde, was embedded in epoxy resin (Epon-812). Ultrathin sections were made and stained with uranyl acetate and lead citrate for electron microscopy.

\section{CASE REPORTS}

Patient 1: A male, aged 68 years, came to hospital because of gradually increasing weakness of the right limbs associated with choking while

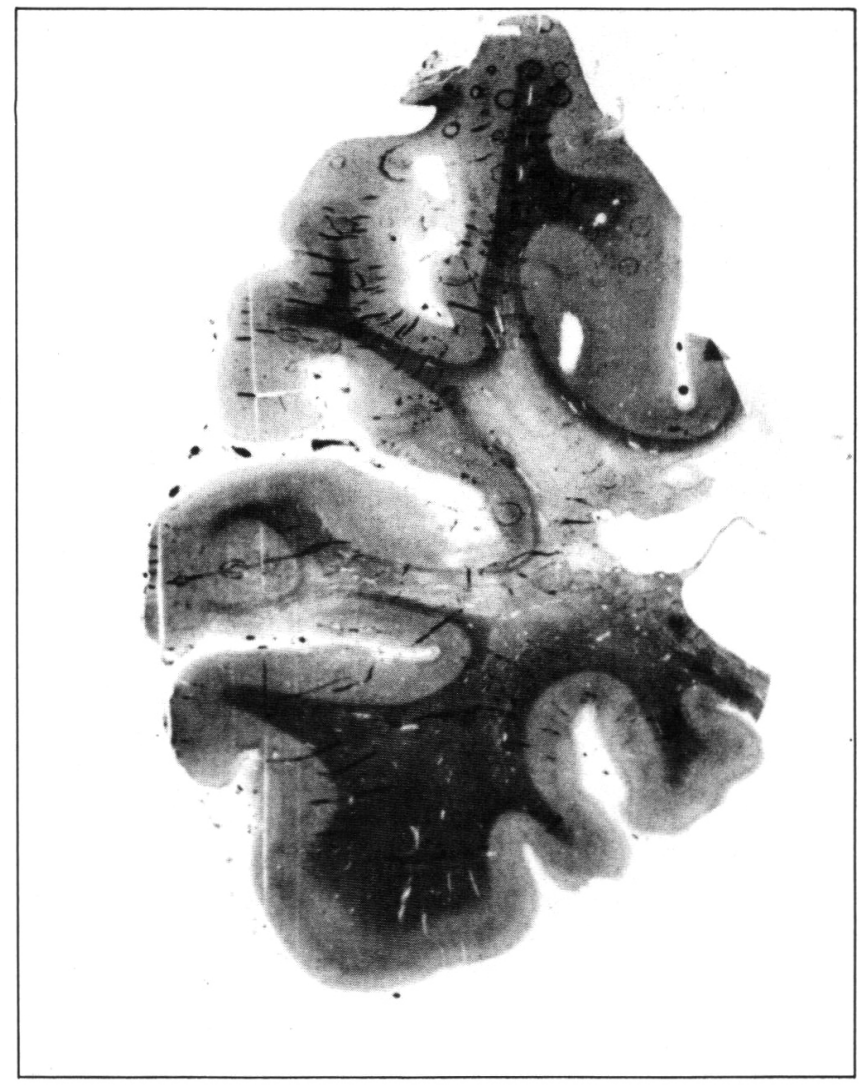

Figure I - Patient 1. Pallor of white matter with sparing of arcuate fibres of the right frontal lobe, probably chronic. Weil stain. swallowing, for 10 days. Three years previously he suffered from left hemiplegia from which he partially recovered. There was no history of hypertension or dementia.

Physical examination on admission revealed lethargy, hemianopsia, facial weakness of the central type, and hemiplegia on the right side, associated with sensory impairment and exaggerated stretch reflexes.

Following admission, the right hemiplegia gradually recovered but mental deterioration became apparent: lack of spontaneous speech or activity, inability to calculate, poor judgement, often sitting idly and occasionally playing with his faeces. His condition deteriorated and he finally died of gastrointestinal haemorrhage 3 months after the onset of his illness.

At autopsy, the heart weighed $269 \mathrm{gms}$ and revealed an old infarct. The lungs showed bronchopneumonia and pulmonary edema. Other body organs were not remarkable, except the brain which weighed $1,182 \mathrm{gms}$ and showed moderate atherosclerosis of the internal carotid and vertebral arteries. Coronal sections revealed an area of softening extending from the left frontal pole to the left parietal lobe, a distance of about $8 \mathrm{~cm}$. There was a $1 \mathrm{~cm}$ haemorragic lesion in the right parietal lobe and a haemorrhage of similar size in the anterior portion of the left putamen. The thalami appeared normal. A myelin stain (Weil) revealed an area in the right frontal lobe, $1.5 \mathrm{~cm}$ in diameter which appeared very pale and demarcated suggesting chronicity (Fig. 1); another in the right parietal lobe $1.0 \mathrm{~cm}$ in diameter (Fig. 2) and two areas in the right parieto-occipital lobe $2.0 \mathrm{~cm}$ in diameter each, with sparing of arcuate fibres also found.

Light microscopy showed an area of old infarction in the right frontal lobe. The arterioles in the basal ganglia and in the cerebral white matter showed no changes. Electron microscopy showed severe splitting of the laminae of myelin sheaths with eccentrically placed axons (Fig. 3 ) in the white matter of the right parietal lobe, in addition to postmortem changes of neurons, myelin, axon, and glia cells.

Patient 2: An 82-year-old woman was admitted because of cough and fever for 2 weeks. Past history was unremarkable except for hypertension and left hemiparesis four years ago.

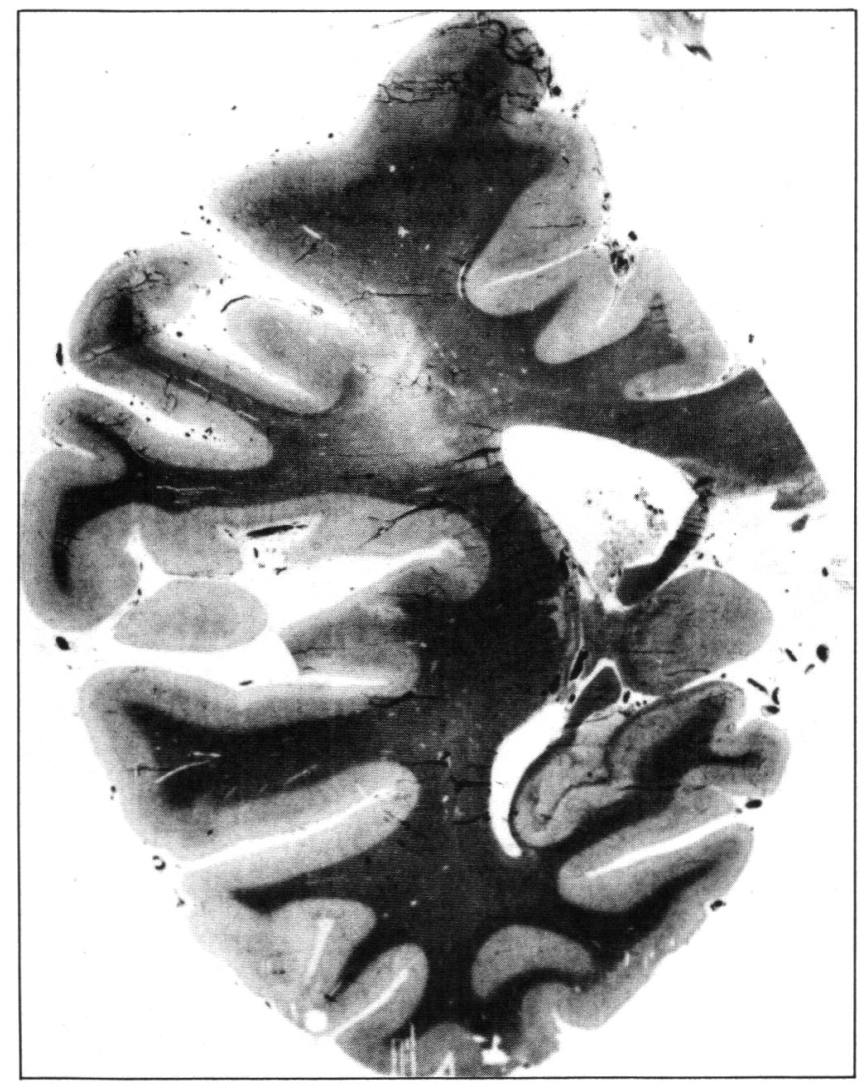

Figure $2-$ Patient 1. Pallor of white matter with sparing of arcuate fibres of the right parietal lobe. Weil stain. 
On physical examination the blood pressure was $90 / 60$. Moist râles were heard over both lung bases. Neurological examination showed clear mentality with slight dysarthria, flattening of left nasolabial fold, deviation of the protruded tongue to the left, and paresis of the left limbs with increased tone, exaggerated tendon jerks and Babinski responses. Thirteen days after admission, the patient died of circulatory shock, one month after the onset of the illness.

At autopsy the brain weighed 1,135 gms. Gyri were narrowed and sulci widened. The internal carotid and vertebral arteries showed moderate atherosclerosis without occlusion. Coronal section revealed a zone of softening, approximately $7.0 \mathrm{~cm}$ in diameter, in the right inferior temporal convolution extending to the occipital lobe; another $0.5 \mathrm{~cm}$ in diameter was found in the right internal capsule at the level of tuber cinereum. Myelin stain (Weil) revealed an irregular area of pallor $2.5 \mathrm{~cm}$ in diameter in the region of the left parietal, and temporal lobes and left lateral ventricle, with sparing of the arcuate fibres (Fig. 4).

Light microscopy showed the areas of softening with degeneration of neurons replaced by gitter cells and hyperplastic astrocytes. The arterioles in the basal ganglia as well as in the cerebral white matter showed no change. Electron microscopy of the area of pallor revealed severe splitting of laminae of the myelin sheath and local thickening of the myelin sheaths to form nodules with a pale, hazy appearance (Fig. 5).

Patient 3: A female, aged 79 years, was admitted because of sudden onset of left hemiplegia and dysarthria. There was no history of impairment of intellect. Blood pressure was 150/90; moist râles were heard in both lungs; atrial fibrillation was associated with a pulse rate of 70 beats/min. She also showed paralysis of gaze to the right and right hemiplegia.

On the second day after admission, her temperature rose to $40^{\circ} \mathrm{C}$ and she became comatose. On the sixth day, massive haemorrhage in the gastrointestinal tract occurred. The patient died on the thirteenth day.

Autopsy disclosed cardiac hypertrophy. The heart weighed $550 \mathrm{gms}$ and had mitral stenosis and incompetence, and aortic stenosis; the myocardium was studded with small scars. Purulent bronchitis and atherosclerosis of the renal arteries were demonstrated. The brain weighed $1,260 \mathrm{gms}$ with thickening of the arachnoid and severe atherosclerosis of internal carotid and vertebral arteries. There was an area of softening $7.5 \mathrm{~cm}$ in diameter at the left Sylvian fissure, involving the left insula and external capsule, and another $4.5 \mathrm{~cm}$ in diameter in the left occipital lobe. Myelin stain (Weil) revealed an irregular area of pallor $2.0 \mathrm{~cm}$ in diameter in the left frontal lobe, with sparing of arcuate fibres. No changes were found in the thalami.

Light microscopy revealed loss of structure at the sites of softening and numerous gitter cells, some of which contained hemosiderin. The arterioles in the basal ganglia and the cerebral white matter showed no thickening of their walls. Electron microscopy revealed splitting of laminae of myelin sheaths and disappearance of axons.

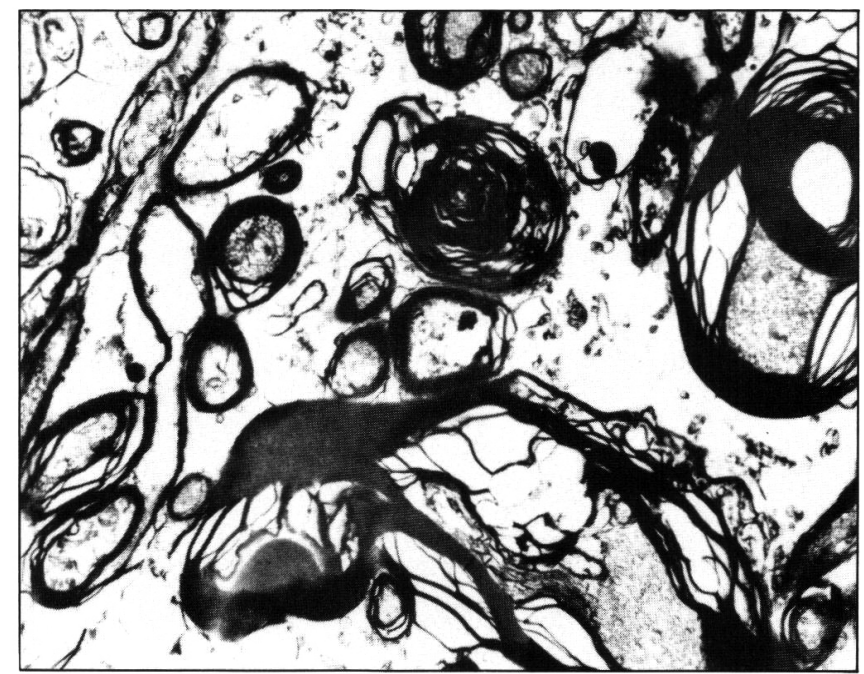

Figure 3 - Patient I. Splitting of the laminae of the myelin sheaths with local thickening and eccentric position of the axons in the right parietal lobe Em: Uranyl acetate and lead citrate X 3.500 (original magnification).
Patient 4: A female 70 years of age was admitted because of clouded mentation and right hemiplegia, following three hours of vomiting and diarrhea. Past history was not contributory except for hypertension of more than ten years' duration. No impairment of intellect had been noticed by the family.

Examination revealed a blood pressure of $200 / 120$, lethargy, motor aphasia, paralysis of gaze, right hemiplegia, and bilateral Babinski

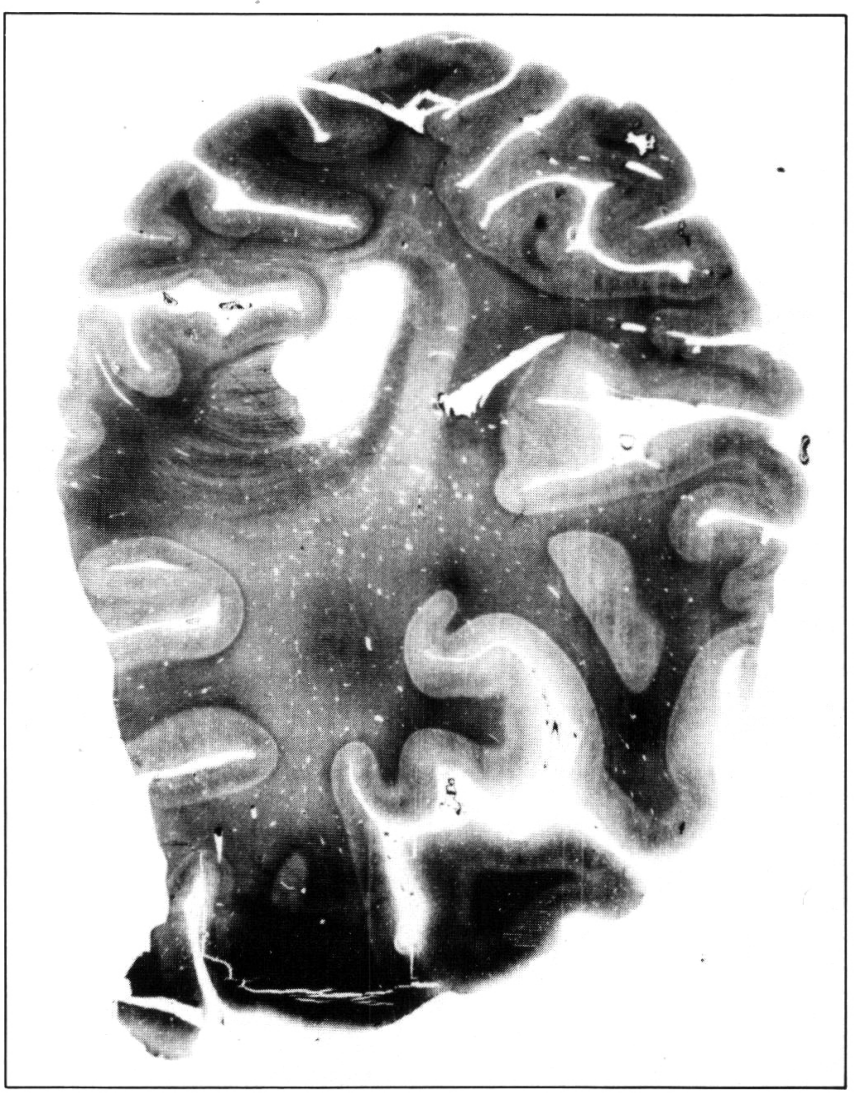

Figure 4-Patient 2. Pallor of white matter with sparing of arcuate fibres of the left parietal lobe. Weil stain.

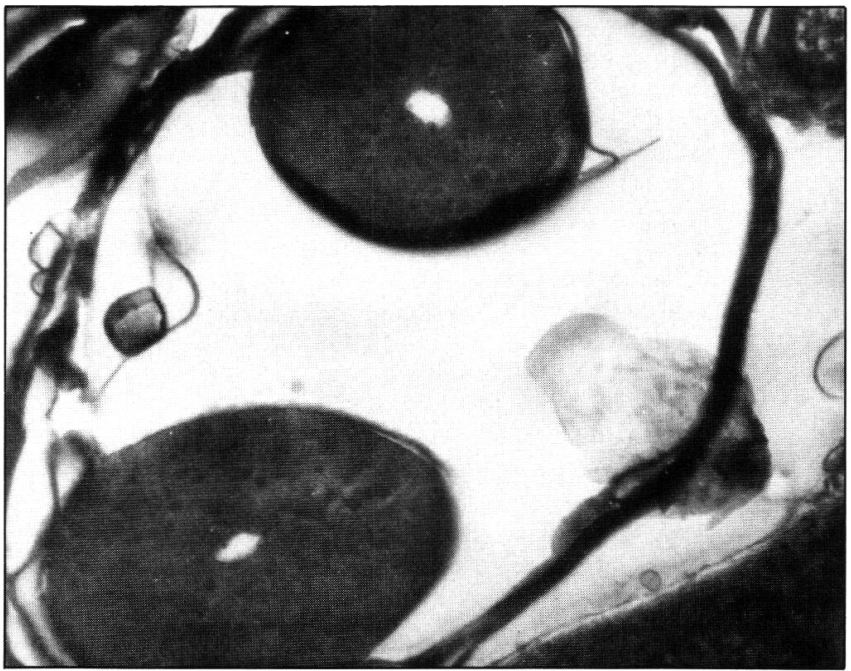

Figure 5-Patient 2. Splitting and local thickening of the myelin sheaths in left parietal lobe. Em: Uranyl acetate lead citrate. X 21,000 (original magnification). 
responses. The patient's condition deteriorated and she died of cardiac arrest 36 hours after the onset of illness.

Autopsy was limited to the brain, which weighed $1,400 \mathrm{gms}$. Slight atherosclerosis of internal carotid and vertebral arteries was found. Coronal sections revealed an area of haemorrhagic softening $6.5 \mathrm{~cm}$ in diameter in the left frontal lobe from $1 \mathrm{~cm}$ in front of the splenium extending to the trigone of the left lateral ventricle. There were haemorrhages of varying size in the tegmentum and base of the pons Myelin stain (Weil) revealed three large areas of pallor: one in the right frontal lobe $4.5 \mathrm{~cm}$ in diameter (Fig. 6), one in the right parietal lobe 4.5 $\mathrm{cm}$ in diameter, and one in the right parieto-occipital region $2.0 \mathrm{~cm}$ in diameter, all showing good preservation of arcuate fibres. No pathological changes were seen in the thalami.

Light microscopy showed the haemorrhagic softening to be due to loss of neural tissue, gitter cells and fresh haemorrhages. The arterioles in the basal ganglia and cerebral white matter showed no thickening of their walls. Electron microscopy showed no definite change in the myelin sheaths or axons despite postmortem changes of the other structures.

Patient 5: A female, 75 years old, was hospitalized because of fever and productive cough for five days. One year earlier she suffered acute left hemiplegia associated with aphasia and incontinence of urine. She had had hypertension for more than ten years.

Physical examination on admission showed a blood pressure of 130/90, and both moist and dry râles in both lungs. There were cachexia and impairment of mentation. Severe painful stimuli elicited a weak response. The pupils were equal but reacted sluggishly to light. The left nasolabial fold was less prominent than the right and the tongue deviated to the left. Left hemiparesis and slight weakness of the right upper extremity were detected. The left plantar response was extensor.

Three days after admission, her level of consciousness deteriorated. She died 11 days after the onset of fever.

At autopsy, the lungs showed diffuse bronchitis with multiple small abscesses. The heart weighed $300 \mathrm{gms}$, with an old infarct of the left ventricle. The brain weighed $1,120 \mathrm{gms}$. Narrowing of the gyri and

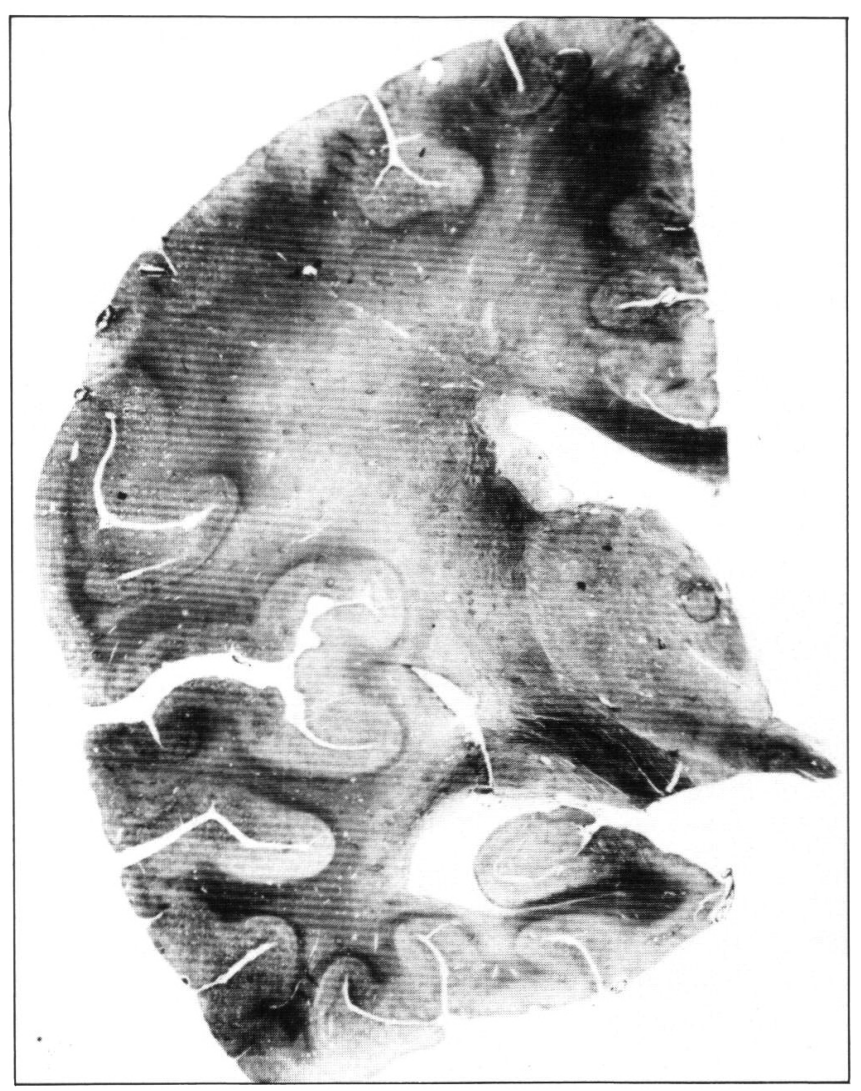

Figure 6-Patien 4. Pallor of white matter with sparing of arcuate fibres of the right frontal and temporal lobes. Weil stain. widening of the sulci were seen. Internal carotid and vertebral arteries showed severe atherosclerosis. Coronal sections revealed numerous small cysts in the right internal capsule, right caudate nucleus, putamen and globus paltidus, and a softening $1.0 \mathrm{~cm}$ in diameter in the left cerebellar hemisphere.

Myelin stain (Weil) yielded scattered small patches of pallor with sparing of the arcuate fibres bilaterally in the coronal section behind the mamillary body.

Light microscopy showed the softenings to be old infarcts. The arterioles of the basal ganglia and those of the cerebral white matter showed thickening of the wall with hyaline change and constriction of the lumen. Electron microscopy showed local thickening of the myelin sheaths to form nodules with displaced axons having a sandlike appearance (Fig. 7).

Patient 6: A woman of 80 years was admitted because of right hemiparesis, incontinence of urine for three days, and choking during swallowing for one day. Shortly before admission mental symptoms appeared: lack of sense of hunger and satiety, polydipsia, and inability to urinate. There had been no history of hypertension.

Physical examination on admission revealed a blood pressure of 190/90, numerous moist râles over both lung bases. Right central facial weakness and right hemiplegia with bilateral Babinski responses were demonstrated.

On the 12th day after admission, severe diarrhea occurred, resulting in a disturbance of serum electrolytes, cardiac arrhythmia, and edema of the extremities. Thirty-eight days after admission. fever. severe fluctuation of blood pressure, and deterioration of consciousness appeared. She expired on the 41 st day.

Autopsy revealed a cardiac weight of $265 \mathrm{gms}$, congestion of both lungs, petechiae in the left renal pelvis, chronic gastric ulcer in the antrum along the greater curvature and leiomyomata of the uterus. The brain weighed $1,065 \mathrm{gms}$ and showed flattening of gyri and narrowing of sulci. Internal carotid and vertebral arteries were severely atherosclerotic.

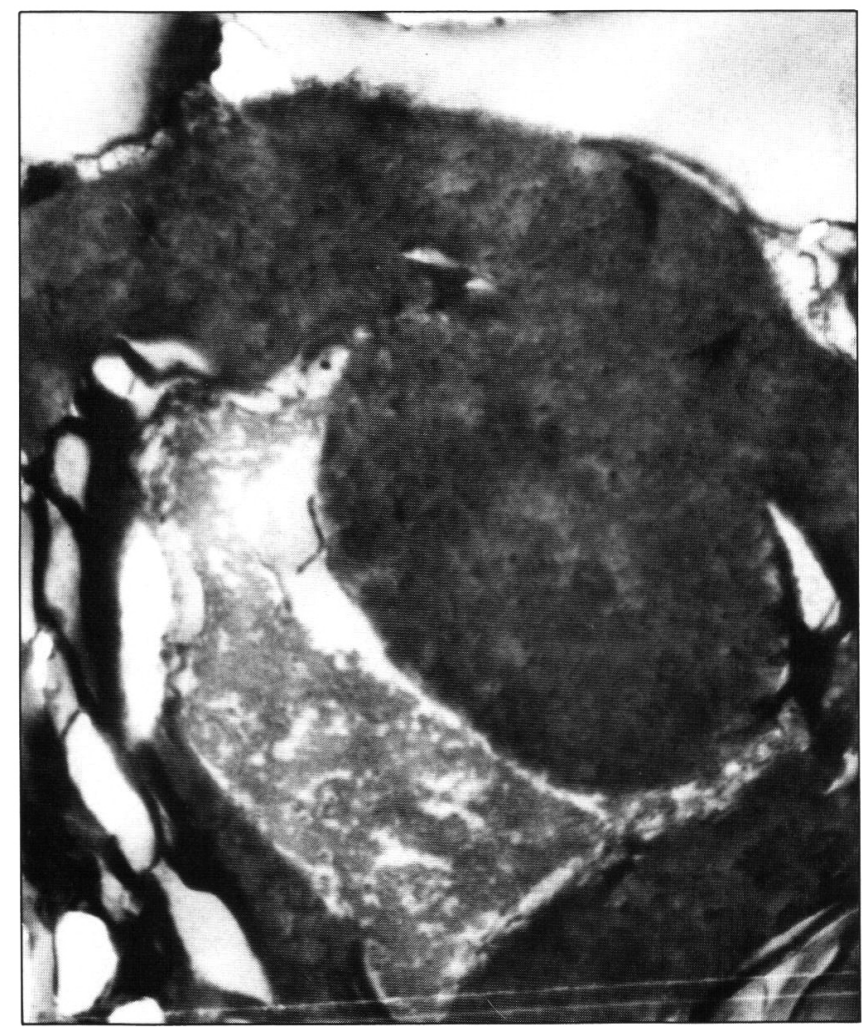

Figure 7 - Patient 5. Local thickening of the myelin sheath; the axis cylinder is displaced and has a sand-like appearance; postmortem changes are seen in other structures. Em: Uranyl acetate and lead cirrate X 17.000 (original magnification). 
Coronal sections disclosed a large softening $11.0 \mathrm{~cm}$ in diameter involving the left frontal, parietal and occipital region including the left insula, caudate nucleus, internal capsule and corpus callosum. but without involvement of the thalamus.

Myelin stain (Weil) showed areas of pallor in the right frontal lobe approximately $1.0 \mathrm{~cm}$ in diameter. with sparing of arcuate fibres. Light microscopy showed softening with loss of neurons. presence of gitter cells, and numerous plump astrocytes. Many lacunae also were demonstrated in the basal ganglia, where the arterioles revealed severe thickening of the wall. hyaline degeneration and constriction of the lumen. The arterioles in the cerebral white matter showed similar changes. Electron microscopy revealed local thickening of the myelin sheaths with reticular appearance of the internal laminae and marked thickening of myelin sheaths.

Patient 7: A man of 56 years had suffered from left hemiplegia for five months before admission. Three years earlier, excision of the right kidney for carcinoma was performed and a year later, metastasis to the left lung were discovered.

After admission, high fever was associated with hyperglycemia and coma. and he died of respiratory and circulatory failure. The course of the illness from the first appearance of hemiplegia and fever was $5 \frac{1}{2}$ months.

At autopsy the heart weighed $535 \mathrm{gms}$. The brain was $1,340 \mathrm{gms}$. No atherosclerosis of internal carotid or vertebral arteries was observed. The external cerebral appearance was normal except for slight bulging of the right hemisphere, especially a widened right precentral gyrus. Coronal section revealed a metastatic tumour $1 \mathrm{~cm}$ in diameter in the right precentral gyrus: another $1 \mathrm{~cm}$ metastasis was found in the left cerebellar tonsil, associated with surrounding edema. No atherosclerosis was detected in the cerebral arteries at the base of the brain

Myelin stain (Weil) revealed a large area of pallor $4.0 \mathrm{~cm}$ in diameter, with sparing of the arcuate fibres. in the left parietal lobe at the level of the mammillary body (Fig. 8).

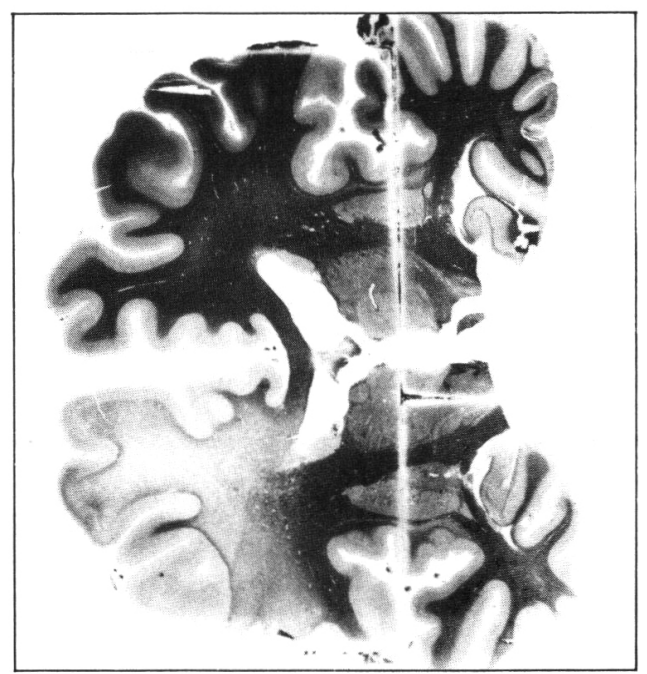

Figure 8 - Patient 7. Pallor of white matter with sparing of arcuate fibres in the frontal lobe. Weil stain.

Light microscopy showed the metastatic tumour to be a clear cell carcinoma. The arterioles in the basal ganglia as well as in the cerebral white matter were normal. Electron microscopy yielded partial splitting of the laminae of the myelin sheaths and an eccentric position of axons.

\section{Discussion}

In only one case (case 3 ) were the areas of pallor of myelin in the same hemisphere as the softening, though they were quite separated from each other. The areas of pallor of myelin were in the hemisphere contralateral to the softenings in patients 1,2 ,
4 , and 6 and contralateral to the metastatic carcinoma in patient 7. The areas of pallor appeared in both hemispheres while the softenings were limited to the right side in patient 5 . The lesions of myelin in all our cases were acute except that of the right frontal lobe in case 1, which was chronic. Only two of the seven cases showed mental impairment (cases 1 and 6).

The common denominator of the 7 cases is the large patch or patches of pallor of myelin (four in case I, one in cases 2 and 3, three in case 4 , only scattered small patches in case 5 , two in case 6 , one in case 7). Sparing of the arcuate fibres, a feature in all our cases, is said to be the pathognomonic feature of subcortical arteriosclerotic encephalopathy (SAE). From a purely pathological point of view, these cases could be considered Binswanger's disease. Clinically, however this conclusion does not seem likely. Five of the 7 cases did not suffer from dementia, and the 2 cases with impaired mentation only showed intellectual abnormality on admission. Nevertheless, Olszewski reported 2 cases of Binswanger's SAE without dementia, one of which was mentally alert on admission and the other had difficulty speaking and a faulty memory. ${ }^{8}$ De Reuck et al. recently reported four similar cases two of which did not have mental symptoms. ${ }^{7}$ The arterioles in the basal ganglia and cerebral white matter showed no changes in cases $1,2,3,4$, or 7 ; and thickening of the walls with hyaline change and constriction of the lumen in cases 5 and 6.

Ultrastructural study of the pale areas showed splitting of laminae of the myelin sheaths (Figs. 3,5) or wave-like or folded appearances of the laminae in places, which may indicate edema if artifact can be excluded. Local thickening of portions of the myelin sheaths into nodules also was seen (Fig. 5, 7), despite preserved axoplasm, apart from postmortem changes of other structures.

From the present material, together with the cases reported in the literature, we may discuss the validity of Binswanger's disease. A variety of focal symptoms and signs have been reported to be characteristic of the encephalopathy. ${ }^{2,6.8 .9-12}$ Some even maintain that discrete strokes, clinical plateaux, and improvement are additional typical features. ${ }^{13}$ Thus the clinical manifestations are very similar to those of multi-infarct dementia, ${ }^{14}$ particularly the single case of Loizou et al. in which there were six definite strokes associated with frequent episodes of dysarthria, confusion, and impairment of consciousness over an 8 year period before death. ${ }^{12}$ Autopsy of this case revealed 7 ( 2 large and 5 small) infarcts and 2 medium-sized areas of pallor of myelin, 1 in the right frontal and another in the left parietal lobes. The lesions of pallor of myelin were perhaps not large enough to cause the dementia which started after his fourth stroke, or three years before death when the fresh pallor patches might not have yet appeared. In the 5 cases of our series without dementia, there were 2 (case 4 and 7) in which the total area of pallor of myelin was much larger than in either of the cases with dementia (cases 1 and 6). This fact raises a question whether the dementia of cases 1 and 6 was due to areas of pallor of myelin. Poppe and Tenustedt reported a case of SAE with no arteriosclerotic changes in vessels in either the subarachnoid space or within the brain substance, particularly in white matter. ${ }^{15}$ Orlando and Orlando also failed to observe pathological changes in the cerebral vessels. ${ }^{16}$ Among our 7 cases, only 2 (cases 5 and 6) showed thickening of the wall with hyaline change and constriction of the lumen of the arterioles in the basal ganglia and cerebral white matter. Thus, from both 
the published data and our own findings, the arteriolar change is not constant in SAE, and causes other than arteriolar lesions should be sought. Furthermore, arteriolar obstruction in white matter would not be expected to result in such diffuse, homogeneous pallor of myelin as seen in SAE, no matter how diffuse the arteriolar lesions.

It is a common experience of neuropathologists that any lesions or anomalies of the penetrating vessels lead to a lacunar state instead of diffuse pallor of myelin. From the anatomical viewpoint, pallor of white matter with sparing of arcuate fibres cannot be caused by deep penetrating vessels or by medullary branches. According to De Reuck the cerebral white matter is supplied by the medullary branches of the cerebral arteries and the end-zones in white matter are situated just beneath the cortex at the level of the arcuate fibres and periventricular white matter. ${ }^{7}$ Should the medullary branches be responsible for the pallor of myelin of the cerebral white matter, the arcuate fibres would bear the brunt of the insult rather than being spared.

Van den Bergh studied the blood vessels of 65 human brains using the benzidine injection method of staining "l'incre de chine" (China ink or India ink) and a radiographic method with contrast substance. ${ }^{17} \mathrm{He}$ found that the cerebral white matter was supplied by long medullary branched centripetally and ventricular branches centrifugally without anastomoses between them. He and others have shown that the zone of demarcation between the centrifugal and centripetal vascular systems was the periventricular white matter. ${ }^{18.19}$ Thus, if there is damage to the cerebral white matter due to arteriosclerotic changes in arteries supplying white matter, the site of the lesion should be deep or periventricular.

The advocates of Binswanger's encephalopathy propose that cerebral arteriosclerosis is the cause of the pallor of cerebral white matter, leading to dementia. According to our data, as well as those reported in the literature, arteriosclerosis of the small arteries is not always present in such cases and arteriosclerotic change, even if present, cannot produce large areas of pallor of myelin with sparing of arcuate fibres.

Stochdorph and Meessen attributed Binswanger's encephalopathy to edematous change and circulatory dysfunction of venous origin, rather than deprivation of oxygen and disturbance of arterial circulation. ${ }^{20}$ This view received support from Van den Bergh's data that the cortex and the white matter situated immediately beneath the cortex were drained by peripheral veins into the plexus of the meningeal veins, while the major portion of the cerebral white matter was drained by central veins entering the subependymal veins, tributaries of the anterior choroidal vein. ${ }^{18}$ When there is obstruction or stasis in the central veins, it is possible to produce pallor of the major portion of the cerebral white matter, perhaps with sparing of arcuate fibres.

Electron microscopy in all 7 of our cases revealed postmortem changes involving both neurons and glial cells: nuclear chromatin became lytic or condensed into masses with organelles difficult to identify; myelin sheaths and axons in the subcortical white matter also underwent postmortem alterations. There were, however 2 pathological changes thought to be antemortem: a) severe splitting of the laminae of the myelin sheath and wave-like and folded appearance of the laminae (Fig. 3), and b) local thickening of the myelin sheaths so severe that they became pale, hazy nodules, but axons remained rela- tively preserved, some of them becoming swollen or shrunken with disappearance of organelles or entirely empty (Fig. 3). The myelin sheaths in the chronic pale zones in the frontal lobe of case I showed no change perhaps explained by resolution of an acute process. The above ultrastructural changes strongly suggest that the pale areas are most likely due to edema. Feigin and Popaff were of the opinion that the pallor of myelin was the late effect of cerebral edema of various causes. ${ }^{21}$ They also thought that thick-walled hyalinized vessels in hypertensive disease were the result and not the cause of cerebral edema. The nature of the pallor of myelin with sparing of the arcuate fibres would be consistent with hypoxic-ischaemic leukoencephalopathy. Ginsberg et al. reported three cases of hypoxic-ischaemic leukoencephalopathy due to hypotension and respiratory depression. ${ }^{22}$ There was sparing of the subcortical arcuate fibres in their case 3 . Lumsden thought that anoxic-ischaemic process was one of the pathogenetic mechanisms. ${ }^{23}$ Ginsberg et al. studied the effect of $\mathrm{CO}$ poisoning on 19 rhesus monkeys and found that the size of the white matter lesions correlated with the degree of metabolic acidosis and systolic hypotension sustained during $\mathrm{CO}$ exposure, but not with the extent of hypoxia per se. ${ }^{24}$ They also maintained that leukoencephalopathy has been observed in anesthesia accidents, cardiac arrest, postoperative shock, hypoglycemia, strangulation and various drug intoxications. All 7 of our cases had either circulatory shock (case 1, 2, 3 and 5) or failure of circulation and respiration (case 4, 6 and 7), as the terminal event and the pathological change coincided well with cerebral edema caused by hypoxic-ischaemia, hypotension or hypercapnia. From the clinical histories and pathological changes of our 7 cases, supported by the data in the literature, the pathological picture of massive pallor of myelin with sparing of arcuate fibres cannot be the direct result of the arterial change, nor can it be regarded as a disease entity, but can only be considered the result of cerebral edema due to various causes.

Loizou et al. made a clinical and radiological investigation of SAE with CT and cited a case (patient 3 ) showing a low density area which partially resolved after evacuation of the haematoma. ${ }^{4}$ The authors thought that the low attenuation of white matter of this patient was due to edema and hypertension rather than to white matter demyelination or gliosis. They also derived support for this view by their patient 5 who presented with an acute stroke (dysphasia) and hypertension; the CT scan showed a left temporal infarct and low attenuation of white matter in the frontal and parietal regions, the latter resolving considerably after treatment with hypotensive medication for 2 weeks. These clinical data lend support to our view. Thus pallor may be present without arteriosclerosis as in our five cases and others reported in the literature ${ }^{15.16}$ and may not cause dementia as five of our cases, and those of Olszewski ${ }^{8}$, and two of De Reuck et al.'s cases demonstrate. ${ }^{9}$

If one accepts that the only dementia caused by arteriosclerosis is the result of multiple infarcts ${ }^{14}$ a question may then arise in rare cases (such as case 3 of Jellinger and Neumayer) in which the patient's intellectual deterioration could not be explained by infarcts in the brain. In this case, nevertheless, there was damage to the thalamus as clearly stated in the original article: 'Im Putamen und Thalamus multiple perivasale Necrosen und Parenchym-veränderungsherde (Stadium III)". " Castaig et al. reviewed thalamic dementia and reported two cases due to vascular lesions. ${ }^{25}$ It has been well documented that bilateral 
lesions in thalamus due either to tumour or vascular lesion can give rise to dementia. ${ }^{26-28}$ This case may be a case of small multi-infarct dementia. ${ }^{14}$

According to Crapper-McLachlan (personal communication) no cases which meet the criteria outlined by Binswanger have been found in over 25,000 brains examined at the University of Toronto since 1931.

Based on our seven cases and those reported in the literature, together with Crapper's experience, we can confidently say that all dementia due to arteriosclerosis is due to cerebral infarcts of large or small sizes; the patches of pallor of myelin with sparing of arcuate fibres, being usually fresh, are the results of hypoxic-ischaemia, hypotension or acidosis as a concomitant phenomenon which contributes little to the cause of the dementia.

\section{REFERENCES}

1. Binswanger $O$. Die Abgrenzung de allgemeinen progressiven Paralyse Berl Klin Wochenschr 1894: 31: 1103-1105. 1137-1139. 1180-1186.

2. Mikol MJ. Maladie de Binswanger et formes apparentées. Contribution à l'étude des leucoencéphalopathies artérioscléreuses. Rev Neurol (Paris) 1968: 118: 111-132.

3. Burger PC. Burch JG. Kunze U. Subcortical arteriosclerotic encephalopathy (Binswanger's disease): a vascular etiology of dementia. Stroke 1976: 7: 626-631.

4. Laizou LA. Kendall BE. Marshall J. Subcortical arteriosclerotic encephalopathy: a clinical and radiological investigation. J Neurol Neurosurg Psychiat 1981: 44: 294-304.

5. Rothschild D. Neuropathologic changes in arteriosclerotic psychoses and their psychiatric significance. Arch Neurol Psychiat 1942: 48: 417-436.

6. Olszewski J. The myth of Binswanger Disease (Discussion). J Neuropath Exp Neurol 1961: 20: 312 .

7. De Reuck J. The cortico-subcortical arterial angio-architecture in the human brain. Acta Neurol Belg 1972: 72: 325-329.

8. Olszewski J. Subcortical arteriosclertic encephalopathy: Review of the literature on the so-called Binswanger's disease and presentation of two cases. World Neurology 1962: 3: 359-375.

9. De Reuck J. Crevits L. De Coster W. et al. Pathogenesis of Binswanger chronic progressive subcortical encephalopathy. Neurology 1980: 30: $82(0-928$

10. Garcin R. Lapresle J. Lyon G. Encéphalopathie sous-corticale chronique de Binswanger: Étude anatomoclinique de trois observations. Rev Neurol (Paris) 1960: 102: 423-440.

11. Jellinger K. Neumayer E. Progressive subcorticale vasculare Encephalopathie Binswanger: Eine klinish-neuropathlogische Studie. Arch Psychiat Nervenkr 1964: 205: 523-554.
12. Loizou LA. Jefferson SM. Thomas Smith W. Subcortical arteriosclerotic encephalopathy (Binswanger type) and cortical infarct in a young normotensive patient. J Neurol Neurosurg Psychiat 1982: 45: 409-4I7.

13. Caplan LR. Schoene WC. Clinical features of subcortical arteriosclerotic encephalopathy (Binswanger disease). Neurology 1978: 28: $1206-1215$.

14. Hachinski VC. Lassen NA. Marshall J. Multi-infarct dementia: a cause of mental deterioration in the elderly. Lancet 1974:2: 207-210.

15. Poppe W. Tenustedt A. Ein Beitrag Zur Encephalopathia subcorticalis Binswanger. Psychiat et Neurol 1963: 145:27-35.

16. Orlando R. Orlando YJC. Contribución al conocimiento de las leucocefaloses tipo Binswanger. Comptes-Rendues Ve Congr Neur Intern lisbonne 1953: Lisboa 1954: 4: 60-74.

17. Van den Bergh R. Les Caractères fondamentaux de l'angioarchitecture sous-corticale du telencephalon humain. World Neurology 1962: 7: 546-560.

18. Van den Bergh R, vander Eeken H. Anatomy and embroyology of the cerebral circulation. Progr Brain Res 1968: 30: 1-25.

19. De Reuck J. The human periventricular arterial blood supply and the anatomy of cerebral infarctions. Eur Neurol 1971: 5: 321-334.

20. Stochdorph O. Meessen $\mathrm{H}$. Die arteriosklerotische und die hypertonische Hirnerkrangung. Handbuch d spez path Anat u Histol 1957: 13/1B: 1465-1510.

21. Feigin I. Popaff N. Neuropathological changes late in cerebral edema: the relationship to trauma, hypertensive disease and Binswanger's encephalopathy. J Neuropath Exp Neurol 1963: 22: $500-511$.

22. Ginsberg MD. Hedley-Whyte ET. Richardson EP Jr. Hypoxicischaemic leukoencephalopathy in man. Arch Neurol 1976:33: 5-14.

23. Lumsden CE. Pathogenetic mechanisms in the leucoencephalopathies in anoxicischaemic processes. In: Vinkin PJ. Bruyn GW. eds. Disorders of the Blood and Intoxications: Handbook of Clinical Neurology, Amsterdam. North Holland Publishing Co 1970; 19: 572-663.

24. Ginsberg MD, Myers RE, McDonagh BF. Experimental carbon monoxide encephalopathy in the primate: II Clinical aspects neuropathology and physiological correlation. Arch Neurol 1974: 30: $209-216$

25. Castaigne P. Buge A. Combier J, et al. Démence thatamique d origine vasculaire par ramollissement bilatéral. limité au territoire du pédicule rétro-mamillaire: À propos de deux observations anatomocliniques. Rev Neurol (Paris) 1966: 114: 89-107.

26. Bousser MG. Les conceptions actuelles des démences artériopathiques. L’Encéphale 1977: 3: 357-372.

27. De Boucaud P. Vital C. de Boucaud D. Démence thalamique d'origine vasculaire. Rev Neurol (Paris) 1968: 119: 461-468.

28. Castaigne P. Lhermitte F. Buge A. et al. Paramedian thalamic and midbrain infarct: clinical and neuropathological study. Ann Neurol 1981: 10: 127-148. 